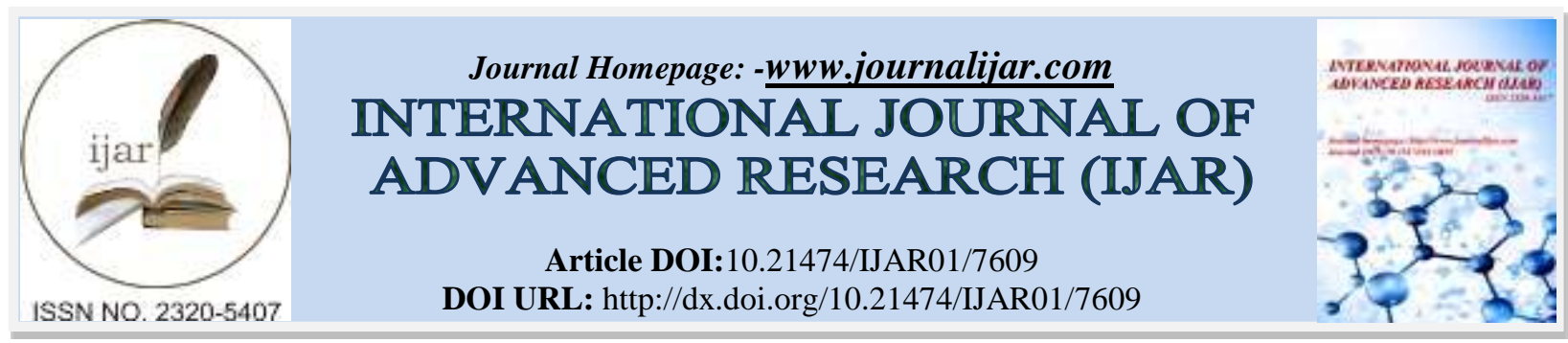

REVIEW ARTICLE

\title{
APPLICATIONS AND TECHNIQUES OF TRANSGENIC ANIMALS IN DISEASE DIAGNOSIS AND THERAPEUTIC TARGETS.
}

Arnav Padhi.

School of Biotechnology, KIIT University, Bhubaneshwar, India.

\section{Manuscript Info}

Manuscript History

Received: 22 June 2018

Final Accepted: 24 July 2018

Published: August 2018

Keywords:-

Transgenic animals, Gene Transfer,

Mice, Ethics, milk.

\section{Abstract}

Transgenic animals are those whose genetic material has been altered and carry the genes of other organisms. This technology is one the latest trends used in the field of biotechnology. It is used to integrate the transgene into the organism and produce the desired trait in an industrial scale.Each has its own advantages and disadvantages and needs further studybecause of unresolved technical and safety issues. They serve as models to study human diseases and its diagnosis and have shown to increases resistance,productivity, hardiness, and feed efficiency and in use of precliniacal studies. In this review the strategies used for drug discovery, preclinical trials using transgenic animals has been discussed and the production of recombinant milk.

Copy Right, IJAR, 2018,. All rights reserved.

\section{Introduction:-}

The first transgenic animal was produced in 1981 by successful introduction of a gene for rat growth hormone into the fertilised eggs of mice, it was carried out by Ralph Brinster and Palmiter. The injected DNA was constructed so as to coding portion of the rat gene The foundation of DNA isolation and gene cloning technology, which help to the study of foreign genes insertion in to mammalian cells. All are based on the introduction of the DNA into a single cell that contributes to the development of the animal. The transgenic methods used are Microinjection, Embryonic Stem Cell Transfer, Retroviral mediated gene transfer.

Transgenic animals are produced with the purpose of producing better and good quality breed, increased in milk yield, as well as to produce organs to meet the demand for organ transplantation. These animals can change the direction of evolution which can cause genetic drift. The embryo can have a extra functional gene which was artifically introduced into it, the gene which was introduced can knock out the function of another gene in the embryo. As new transgenic technologies develop, its applications will grow in course of time in terms of increased growth rate, life stock and productivity.

\section{Preclinical Studies involving Transgenic Animals:-}

These processes have a high attrition rate and less than $10 \%$ of the compounds tested The cost of launching a new drug exceeds $\$ 1$ billion. One solution to the significant challenges faced in the development of new drugs and combination therapies is the use of low-cost, in vivo animal models.

Techniques for manipulating the mouse genome and mouse embryos have become increasingly sophisticated. For example, Knock-in models, have been developed in which transgenes are inserted in the specific position of the 
genomw has been develop[ed The sophisticated mouse models that have been generated through these advances in mouse engineering technologies are useful for drug discovery and preclinical trials.

Targeted transgenesis, has helped to reduce the cost and enhance the timeline of GEMM generation. This technique also allows the transgene to be stably integrated and expressed in the mouse genome. It provides an attractive alternative to random transgenesis by pronuclear injection or lentiviral infection. Transgene integration mediated by recombination at specific sites such as the ROSA26 or COL1A1 loci. The ROSA26 locus has become the locus of choice for targeted transgenesis because of the autosomal location, the ubiquitous expression. The recombinase mediated cassette exchange (RMCE) method was developed to enhance the efficiency of targeted transgenesis at the ROSA26 locus in ES cells.

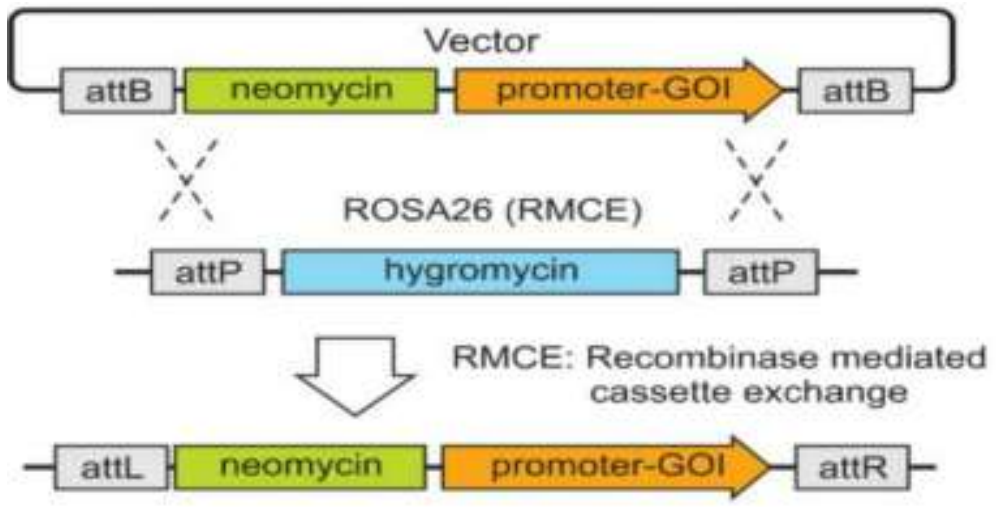

Figure 1:-Targeted transgenesis at the ROSA26 Locus by recombinase mediated cassete exchange (RMCE) results in genomic integration of Target gene into the Rosa26.10 allede of the mouse ES cells

Production of Recombinant Proteins and milk produced by transgenic animals.

The expression vectors used to produce transgenic mice contain regulatory portions of the gene. The expression vectors consists of a 5' region having a promoter, introns, exons. They consist of 3'untranslated region (UTR) which greately vary in size from 0.5 to $10 \mathrm{~kb}$. The Beta caesin gene promoter is effectively used to produce target proteins. The human lactoferin gene was was expressed using the vector $\mathrm{pBC} 1$. The concentration of Lacoferin was not more than $4 \mathrm{mg} / \mathrm{ml}$. Untranslated sequences of the $\beta$-casein genes in the construct are considered to enhance the stability of the mRNA of the transgene in the mammary gland.

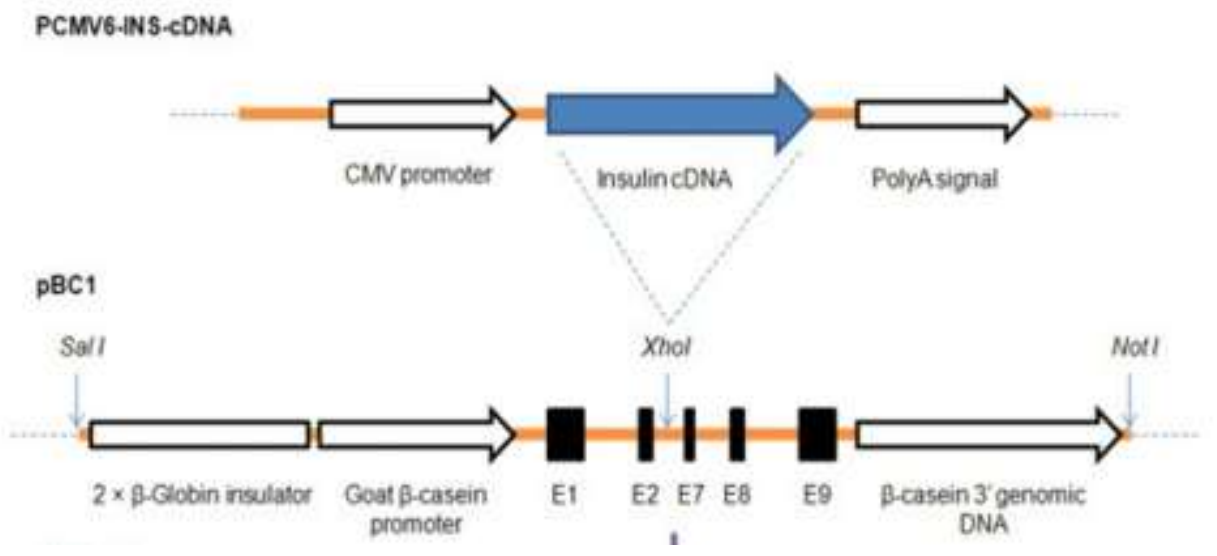

Figure4:-Schematic representation of transgenic construction. The cDNA in thepCMV6-XL5-INS-cDNA was amplified and inserted into the $\mathrm{pBC} 1$ vector at the Xho I site, 


\section{Human Proinsulin}

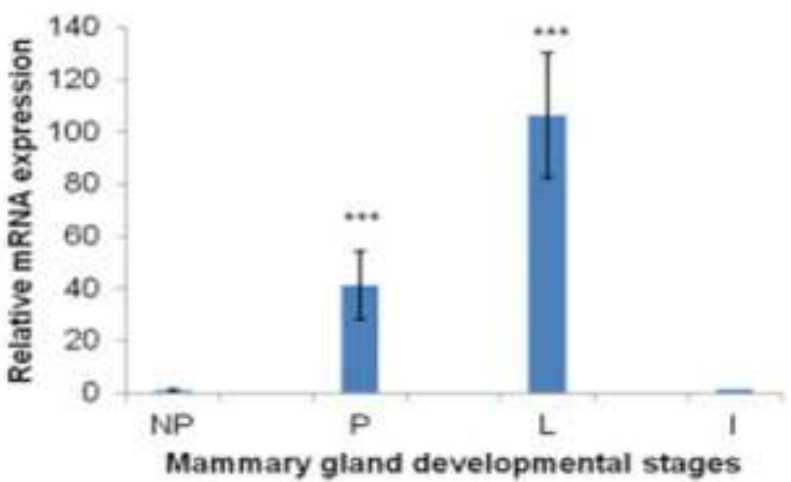

Figure 5:-Analysis Of Human Proinsulin Transcripts In The Mammary Gland Of Transgenic Mice

Somatic Cell Nuclear Transfer is widely used to generate transgenic pigs and cows which haveimproved meat or milk quality. However, researches about the application of transgenic cloned goats are less. Dairy goatsare preferable to other species to produce recombinant proteins in milk for the following reasons. First, dairy goats producemore milk than rabbits and mice.

In 2000, AgResearch generated their first transgenic cows. These cows produced modified or 'designer' milk. AgResearch's first transgenic cows had extra bovine (cow) kappa casein genes inserted in their genome. Casein proteins come in 4 different variants: alpha-s1, alpha-s2, beta and kappa casein. Each variant has its own amino acid composition, genetic variations and functional properties. The milk from casein transgenic cows contained double the levels of kappa casein than milk from control cows. The milk from the transgenic cows had a slightly yellowish tinge when compared with normal milk.

Table 1:-Components in cow's milk

\begin{tabular}{|l|l|}
\hline Cow milk Component & Approximate Percentage \\
\hline Water & 86.5 \\
\hline Milk Sugar & 4.8 \\
\hline Fat & 4.5 \\
\hline Proteins & 3.5 \\
\hline Vitamins and minerals & 0.7 \\
\hline
\end{tabular}

Table 2:-Proteins produced in milk of transgenic animals

\begin{tabular}{|l|l|l|}
\hline Proteins & Animal Species & Expression level in milk(g/l) \\
\hline Interleukin 2 & Rabbit & 0.005 \\
\hline Fibrinigen & Sheep & 5 \\
\hline tPA & Goat & 6 \\
\hline Protein C & Pig & 1 \\
\hline Insulin like growth factor & Rabbit & 1 \\
\hline Erythropoietin & Rabbit & 0.005 \\
\hline
\end{tabular}

The expression levels of recombinant human proinsulin in the transgenic milk were shown to rangefrom 1.2 to $8.1 \mu \mathrm{g} / \mu \mathrm{l}$. The lowest level of human proinsulin $(1.2 \mu \mathrm{g} / \mu \mathrm{l})$ expressed in the milk of transgenic cows. The average production of milk by goat is $3 \mathrm{~kg}$ per day and of cow is $40 \mathrm{~kg}$ per day. On an average they would produce $3 \mathrm{~g}$ or 48 $\mathrm{g}$ of proinsulin per day.

\section{Applications of Transgenic Animals in the Society}

Transgenic animals are used as models to study human diseases and cancers, so that they can study the affects it has on the body. They hope this will help them find a cure for thedifferent diseases and cancers and identify specific genes responsible for the diseases. Transgenic mice overexpressing a dominant negative mutation(K577M-WRN) 
has been used as a model to study Werner syndrome. Various knock out rodents are used to study Alzheimer's disease (AD), PD, Huntington's disease.

Knockouts therefore show huge promise for identifying \& validating new drug targets among the tremendous number of potential targets revealed by the sequencing of the human genome. In recognition of this, national funding organisations have recently established two international consortia whose remit is the centralised \& systematic generation \& characterisation of mouse knockout models.

Approximately about 250000 people are alive due to the successful transplantation. Pigs which are genetically modified can be used as a source animal for tissues and organs in human beings for transplantation purpose. In canada, a national survey on xenotransplantation showed that only $48 \%$ found acceptable for 'the use of animals as a source of living cells, tissues or organs to prolong human life.

Toxicity sensitive transgenic animals have been produced for chemical safety testing. In 2001, two scientists at nexia biotechnologies in canada spliced spider genes into the cells of lactating goats. The goats began to manufacture silk along with their milk by extracting polymer strands from the milk and weaving them into thread, the scientists can create a light, tough, flexible material that could be used in making tennis raquet strings.

Trasngenic swine has been used to optimize production of meat. They are considered excellent models to study cardiovascular diseases, lipoprotein metabolism,

Transgenic animals are used for production of proteins such as human protein $\mathrm{c}$ which is used in the treatment of thrombosis.. This process is less expensive than production of protein through culture of human cells. Transgenic cows expressing lactoferin, lysozyme have been obtained in china to produce modified milk. They also produce a milk called lysostaphin, at a concentration of $0.014 \mathrm{mg} / \mathrm{ml}$ is bacteriocidal against staphylococcus infection. Production of human serum albumin helps in maintaining blood flow in the body. Transgenic goats whose milk contains human recombinant human lysozyme at a concentration of $0.27 \mathrm{mg} / \mathrm{ml}$ has been obtained in us and its mammary glands are used to produce monoclonal antibodies. Transgenic animals are also used for testing of drugs or to undertake studies which is always not possible on human beings.Another example of transgenic animals produced is used to understand a particular process of transgenic Zebra-fish, which are important tools to help in understanding gene action during embryo development.

\section{Ethical issues surrounding Transgenic animals}

Transgenic animals have potentially broad applications in the improvement of animal production quality, the studies of human disease models. However, there are many problems that need to be resolved for transgenic animal studies.

Transgenic animals have helped in improving the quality of milk production but at the same time they tend to have a much shorter life span than normal animals. The integration efficiency of extrinsic genes at the target site is low and unstable, and what affects the intrinsic gene, damages the host's genome. Many of the embryos that undergo genetic engineering procedures do not survive, and of those that do survive only a small proportion (between 1\% to $30 \%$ ) carry the genetic alteration of interest This means that large numbers of animals are produced to obtain genetically engineered animals that are of scientific value, and this contradicts efforts to minimize animal use. Interfering with the genome by inserting or removing fragments of DNA may result in alteration of the animal's normal genetic homeostasis. For example, many of the early transgenic animals which were produced had a range of unexpected side effects including lameness, susceptibility to stress, and reduced fertility, sterility.

A significant limitation of transgenic technology technology is the prospect that cloned offspring may suffer some degree of abnormality. Studies have revealed that cloned animals may suffer from developmental abnormalities, including extended gestation; large birth weight, inadequate placental formation. The inserted gene of interest may affect the host,contaminate other genes, and produce a variety of threats to ecological balance and species diversity. Many of the knock out mice die while they are in their embryo stage before the researches has the chance to use this model.

Transgenic animal production may also lead to food-safety problems such as inadvertent allergies or toxicities. Therefore laws and regulations must be made for the betterment of mankind. 


\section{Conclusion:-}

The creation of transgenic animals has resulted in the use of high order species such as dogs to low order species such as mice. Throughout history, transgenic animal has made significant contributions to human health and wellbeing. Chimera generation by injecting the pluripotent cells adds a new dimension to animal breeding. all these developments will provide new ideas and bring important changes in the field of medicine, health and lifestock. in particular it will improve the production of bioreactors, lifestock, drug production. production of organ culture for human transplantation will help in thousands of patients who require organs in order to survive.

\section{References:-}

1. Brinster, R. . The effect of cells transferred into mouse blastocyst on subsequent development.(1974) J. Exp. Med.:1049-1056.

2. Ann N Y Sci.. Using transgenic animal models in neuroendocrine research: lessons from Xenopus laevis. (2009) Apr;1163:296-307.( Pubmed)

3. Wheeler, M. B.et al.Transgenic animals in biomedicine and agriculture: outlook for the future. Animal Reproduction Science.(2003) 79, 265-289

4. Chengyu Lie, Wen Xie, Changyun Gui, Yubin Du.Pronuclear Microinjection and Oviduct Transfer Procedures for Transgenic Mouse Production. (2013). (Pubmed)

5. Yosikhi Takashi, KazurnoiI Hanakova2, Michiko Hayasaka, Kazuto Katoh , Yoshiihiro Kato, T. S. Okada, Hisato Kondoh, Embryonic stem cell-mediated transfer and correct regulation of the chicken d-crystallin gene in developing mouse embryos. (1988)Development 102, 259-269

6. Grosvenor, C. E. et al. Hormones and growth factors in milk. Endocrinology Reviews 14, 710-728 (1993).

7. S Mader,J $\mathrm{H}$ White. A steroid-inducible promoter for the controlledoverexpression of cloned genes in eukaryotic cells.(1993), 90(12): 5603-5607(Pubmed)

8. LeeKF, DeMayo FJ, Atiee SH, Rosen JM. (1988). Tissue-specific expression ofthe ratbeta-casein gene in transgenic mice. NucleicAcids Res. 16:1027-41

9. Van Berkel PHC, Welling MM, Geerts M, van Veen HA, Ravensbergen B,Salaheddine M, Pauwels EKJ, Pieper F, Nuijens JH, Nibbering PH. Large scale production of recombinant human lactoferrin in the milk of transgenic cows. Nature (2002); 20:484-7 [Pubmed]

10. L.chen, 1. lil, d. pang1, z. li, t. wang, m. zhang, n. song,s. ya, 1. x. lai, h. ouyangconstruction of transgenic swine with induced expression of cre recombinase. animal (2010), 4:5, pp 767-771 